\title{
Update and review of Urrets-Zavalia syndrome
}

\section{Atualizando e revisando a síndrome de Urrets-Zavalia}

Otavio A. Magalhães ${ }^{1}$, Claudia L. Kronbauer ${ }^{1}$, Eduardo G. Müller ${ }^{2}$, Carina T. Sanvicente ${ }^{2}$

\begin{abstract}
For more than half a century, Urrets-Zavalia syndrome (fixed dilated pupil) has been described as a postoperative complication of ophthalmic surgery. Since first reported as a complication of penetrating keratoplasty for keratoconus in patients receiving atropine, the characteristic features of Urrets-Zavalia syndrome have been expanded. In previous literature, a total of 110 cases resulted in a fixed and dilated pupil. Increased intraocular pressure (IOP) in the immediate postoperative period, phakia, and air or gas in the anterior chamber appear to be the most important risk factors for Urrets-Zavalia syndrome following ophthalmic procedures. Mannitol, IOP control, the removal of air or gas in the anterior chamber, and iridectomy have all demonstrated utility in managing Urrets-Zavalia syndrome.
\end{abstract}

Keywords: Pupil anatomy and physiology; Pupil disorder prevention and control; Intraocular pressure; Risk factors

\section{RESUMO}

Por mais de meio século, a síndrome de Urrets-Zavalia (pupila fixa e dilatada) foi descrita como uma complicação pós-operatória em oftalmologia. Desde o primeiro relato após ceratoplastia penetrante em pacientes portadores de ceratocone em uso de atropina, seu conceito foi ampliado. Na literatura, um total de 110 casos resultaram em pupila fixa e dilatada. Aumento da pressão intraocular (PIO) no pós-operatório imediato, facia, ar ou gás na câmara anterior parecem ser fatores de risco importantes para o aparecimento da síndrome. Sua prevenção pode ser alcançada com o uso de manitol, controle adequado da PIO e quantidade de ar ou gás na camâra anterior e iridectomia.

Descritores: Pupila/anatomia \& fisiologia; Distúrbios pupilares/prevenção \& controle; Pressão intraocular; Fatores de risco

\section{INTRODUCTION}

Urrets-Zavalia syndrome (UZS; fixed dilated pupil) was first recognized by Castroviejo and published in 1963 by Alberto Urrets-Zavalia $J$ r., who described six cases of atrophic and mydriatic pupil associated with secondary glaucoma following penetrating keratoplasty (PK) in patients with keratoconus ${ }^{(1,2)}$. Other findings of UZS were subsequently reported, including peripheral synechiae, posterior subcapsular opacity, iris ectropion, pigmentary dispersion, and glaukomflecken ${ }^{(3-11)}$.

Other procedures shown to be associated with UZS include trabeculectomy (TREC)(5), deep anterior lamellar keratoplasty (DALK) ${ }^{(12-15)}$, Descemet-stripping automated endothelial keratoplasty (DSAEK) $)^{(16-18)}$, cataract surgery ${ }^{(11,19)}$, goniotomy ${ }^{(20)}$, phakic intraocular lens implant $(\mathrm{IOL})^{(21-23)}$, argon laser peripheral iridoplasty $(\mathrm{ALPI})^{(7)}$, and octafluoropropane injection $(\mathrm{C} 3 \mathrm{~F} 8)^{(24)}$.

Although the reported incidence of UZS is low, the associated visual symptoms can cause limitations in activities of daily life requiring preventative measures by ophthalmic surgeons $s^{(7,14)}$. The purpose of the present review is to identify all reported cases of UZS published prior to December, 2014 in Medline and EMBASE databases, highlight the most prevalent risk factors, and describe measures for the prevention of Urrets-Zavalia syndrome.

\section{RISK FACTORS AND PATHOGENESIS}

There are numerous and conflicting risk factors of the development of UZS. Neurogenic changes, inflammatory response, genetic predis- position, and direct iris trauma have all been posited to contribute to the pathophysiology of UZS $\mathrm{S}^{(7,8,10,25)}$. Early reports indicated the use of atropine in PK as associated with such complications ${ }^{(1)}$. Keratoconus was also suggested to be involved in the pathogenesis of UZS as a result of decreased corneal rigidity and enhanced response to mydriatics ${ }^{(3,26)}$. Intraocular pressure (IOP) elevation, with or without pupillary block, has been implicated as the trigger mechanism of UZS ${ }^{(4,27)}$. Use of viscoelastic substances during surgery have been suspected as toxic to the iris sphincter and a cause of acute rises in $I O P^{(10,11)}$. The use of miotics before and during surgery has been considered prophylactic by some authors and a risk factor of pupillary atrophy by others ${ }^{(4,10,18,25,28)}$.

Urrets-Zavalia posited that iris compression against the peripheral cornea under the effect of intense mydriasis without compromising the ciliary body and pars plana was the most important factor related to the development of UZS $S^{(1,17)}$. Severe iris ischemia was later reported in several angiography studies ${ }^{(4-6,21)}$. The UZS spectrum comprises anterior segment changes ranging from focal pupillary atrophy with posterior pigment layer injury and no stromal involvement to diffuse or sector atrophy, including the iris stroma ${ }^{(28,29)}$. Ischemic events are not thought to contribute to focal cases and pupillary dilation is considered less intense (6 $\mathrm{mm}$ or less). Focal cases of UZS typically respond partially or totally to miotics, which may allow regression of mydriasis. A study on combination therapy with guanethidine and pilocarpine has demonstrated its efficacy and associated miosis in patients with this type of atrophy ${ }^{(28)}$. Conversely, stromal ischemic injury has been reported to be irreversible, promote intense mydriasis (more than $6 \mathrm{~mm}$ ), and not respond to miotics (Figure 1) ${ }^{(14)}$.

\footnotetext{
Submitted for publication: October 14, 2015

Accepted for publication: January 12, 2016

Cornea and External Disease Department, Hospital Banco de Olhos de Porto Alegre, Porto Alegre, RS, Brazil.

Hospital Banco de Olhos de Porto Alegre, Porto Alegre, RS, Brazil.
Ho
}

Funding: No financial support was available for this study.

Disclosure of potential conflicts of interest: None of the authors have any potential conflict of interest to disclose.

Corresponding author: Otavio Magalhães. Rua Mostardeiro, 333/503 - Porto Alegre, RS - 90430-001 Brazil - E-mail: otaviomaga@yahoo.com.br 


\section{LITERATURE REVIEW}

More than 30 studies have been published since the first description of UZS, comprising a total of 110 reported cases $^{(1,4-25,29-42)}$. The mean age of the patients in reported cases was 46.1 years (range: 13-90). Reported surgical interventions include PK (51.8\%), DALK (18.1\%), DSAEK (8.2\%), cataract surgery (8.2\%), ALPI (8.2\%), phakic IOL implantation (2.7\%), TREC (1.9\%), goniotomy (0.9\%), and anterior chamber injection of C3F8 for the treatment of acute hydrops (0.9\%). Diagnoses associated with these interventions include keratoconus (45.2\%), stromal dystrophies (23.7\%), Fuchs' dystrophy (9.4\%), plateau iris syndrome (8.5\%), senile cataract (8.5\%), primary open-angle glaucoma (1.9\%), high myopia (1.9\%), and congenital glaucoma (0.9\%). Individuals affected by bilateral UZS had the same type of ophthalmic procedure on different occasions, corresponding to $8.2 \%$ of all patients. The use of mydriatic drops during or after surgical intervention has been reported in only $26 \%$ of cases, including the first description of UZS. Viscoelastic was injected to completely maintain the anterior chamber in $44.5 \%$ of all surgical procedures. Increased IOP was observed in $59.1 \%$ of patients during the first postoperative day and approximately half of these patients (26.7\%) had maintained elevated IOP measures during the following days. Only $13.1 \%$ of patients with UZS were pseudophakic. Injection of air or C3F8 was performed in $27.3 \%$ of cases, particularly in cases of lamellar keratoplasty $(89.6 \%$ of DALK and DSAEK). The use of miotics (pilocarpine or acetylcholine) was described in $40.9 \%$ of patients during the preoperative or intraoperative periods, with $27.3 \%$ of patients not receiving any type miotic therapy. There was no reference to the use or not of miotics in $31.8 \%$ of the patients.

\section{DISCUSSION}

Many retrospective studies and case and series reports of UZS have been published over the past few decades. UZS reportedly has no predilection for age and has been observed as a postoperative response in both young and elderly patients. We believe that the majority of cases of UZS are related to PK, as this has been the predominant technique during the last century ${ }^{(33)}$. In the 1970s, lamellar keratoplasty was used in less than $5 \%$ of all transplants ${ }^{(43)}$. With the increasing recognition of lamellar techniques and the use of artificial anterior chambers, reports of UZS increased in subsequent decades. The majority of UZS cases were reported in patients with keratoconus, following the same prevalence pattern as other conditions when considering all uneventful corneal transplantations ${ }^{(29)}$. In a retrospective study that analyzed more than 2,000 patients with PK, the incidence of UZS was higher in patients with macular dystrophy

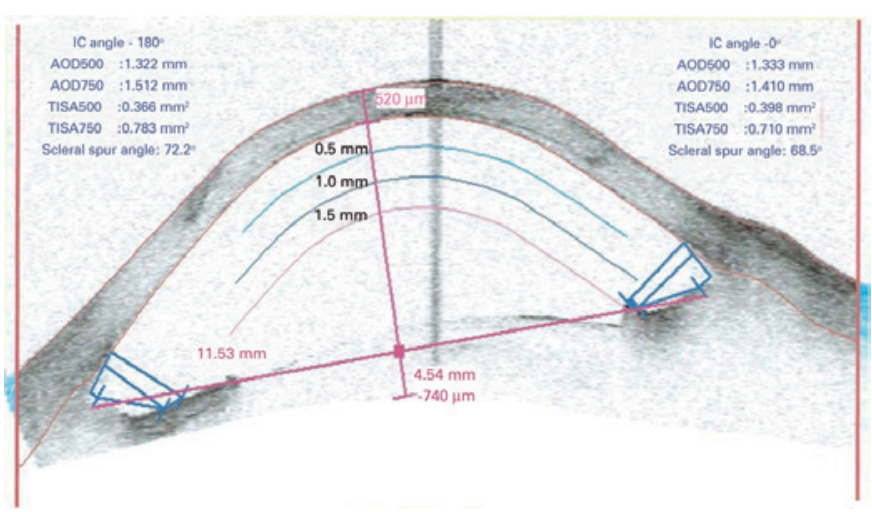

Figure 1. Anterior segment optical coherence tomography (Visante ${ }^{\oplus}$; Carl Zeiss Meditec, Dublin, CA) demonstrating diffuse fixed dilated pupil after DALK with air bubble. A wide open-angle is observed. than in patients with keratoconus ${ }^{(7)}$. We believe that patients with keratoconus are not at increased risk of UZS, as stated in previous studies ${ }^{(26)}$. Increased IOP during and immediately after presentation of UZS has been verified in the majority of reported cases; however, the maintenance of ocular hypertension was not clearly demonstrated in these cases $^{(34)}$. This pattern has previously been suggested by some authors ${ }^{(2,5)}$. However, the causal relationship between increased $\mathrm{IOP}$ and iris ischemia remains unclear. Progression to secondary glaucoma is reportedly observed in approximately one quarter of cases and should not be considered a definitive characteristic of UZS (2). A retrospective study demonstrated a statistically significant increase in IOP within the first $24 \mathrm{~h}$ after surgery in patients undergoing PK for keratoconus ${ }^{(35)}$. Mydriatic instillation during and after the procedure was reportedly performed in a quarter of patients, including the cases originally described by Urrets-Zavalia. Our observations, in corroboration with those of other authors, indicate atropine does not increase the risk of UZS development ${ }^{(32,44-45)}$. In fact, it is questionable whether the use of these measures prevents iris injury ${ }^{(13)}$.

The mechanisms underlying pupillary block remain controversial. It was believed that acute angle closure was required to initiate the pupil atrophy process ${ }^{(5,12,39)}$. Recently, several cases have been described with the absence of pupillary block ${ }^{(10,40)}$. We observed that angle closure was not present in the majority of patients with UZS. The proposed mechanism for iris ischemia in lamellar transplantation is compression against the lens as a result of the injection of large amounts of air or gas into the anterior chamber (Figure 2).

The vast majority of UZS cases are observed in phakic patients. This may explain the limited number of reported cases of UZS in patients undergoing cataract extraction. Protective measures against UZS have also been described, such as iridectomy and intravenous hyperosmotics ${ }^{(8,27)}$. The use of $20 \%$ mannitol has been reported to decrease the incidence of UZS from $4 \%$ to $1.5 \%(46)$. Hyperosmotic agents have demonstrated efficacy in decreasing vitreous volume and subsequently attenuating iris compression due to the lens. Ensuring anterior chamber formation as soon as possible during surgery may also prevent iris strangulation ${ }^{(8)}$. Prophylactic iridectomy or YAG laser iridotomy a few days prior to surgical intervention appear to have efficacy in decreasing risk of pupillary block ${ }^{(2,9,46)}$. However, this practice remains controversial, and some authors have reported

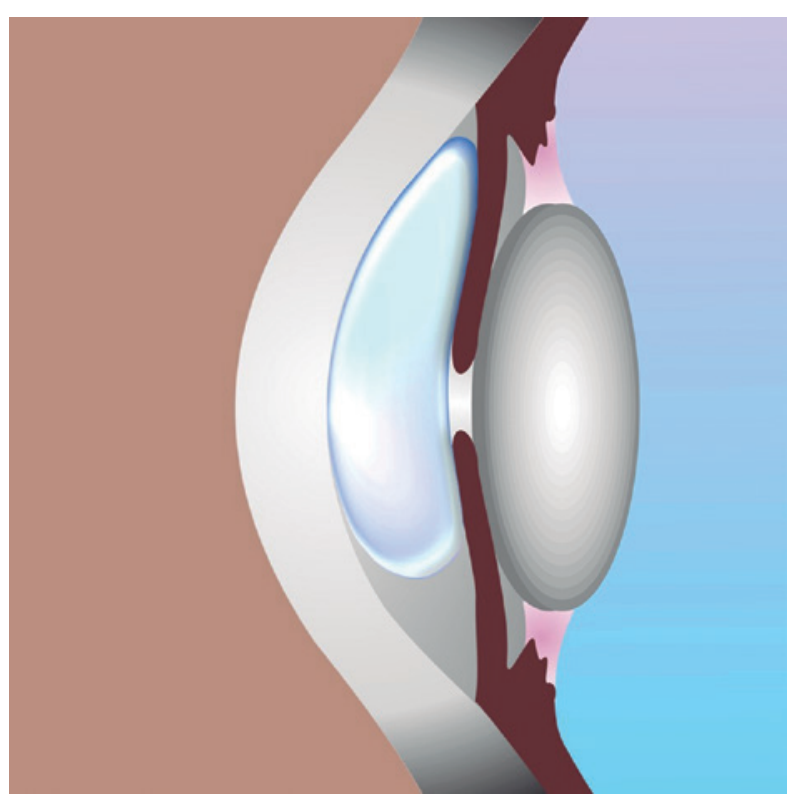

Figure 2. Voluminous air bubble in the anterior chamber compressing the iris against the lens. 
that these therapies provide no benefit(11). Careful management of surgical equipment, such as trephines and scissors, may also prevent iris damage ${ }^{(8)}$. There are currently no specific treatments for diffuse pupillary atrophy. Corneal tattooing, specialty contact lenses, and artificial iris implants are options for glare reduction and appearance improvement. In focal atrophy, miotics such as guanethidine and pilocarpine have demonstrated efficacy in treating UZS and attenuating mydriasis ${ }^{(28)}$

Direct neuronal injury may also be involved in the development of pupillary atrophy. Patients undergoing ALPI may be at risk of damage to the radial parasympathetic fibers of the pupillary constrictor muscle, explaining the observed cases of UZS (7). Likewise, the observation of UZS in both eyes of some patients may indicate a genetic predisposition of the iris sphincter to ischemia in selected corneal pathologies ${ }^{(8)}$. Some authors have attributed the persistence of viscoelastics in the anterior chamber to IOP elevation and UZS. Intraoperative use of viscoelastics was performed in less than half of patients in previous reports. However, the use of viscoelastics is unlikely to be associated with UZS because their use is extremely widespread in cataract extraction surgery and significant pupillary atrophy is not observed following these procedures ${ }^{(47)}$. Despite a lack of data in almost a third of previously reported cases, the use of preoperative and intraoperative miotics was observed in the majority of cases, indicating that these drugs may not prevent irreversible pupil dilation ${ }^{(20,48)}$. Last year, a major review did not address the importance of phakia and the use of miotics in UZS (32).

\section{CONCLUSION}

Patient undergoing keratoplasty for the treatment of any corneal pathology, mainly phakic, with increased IOP in the immediate postoperative period and with air or gas left in the anterior chamber are at increased risk of UZS. We believe that the use of viscoelastic or mydriatic substances during or after surgery is not associated with risk of UZS. Pilocarpine and acetylcholine have not demonstrated efficacy in preventing UZS. However, intravenous use of mannitol, IOP control in the immediate postoperative period, and avoidance of massive air or gas injection into the anterior chamber may decrease the incidence of UZS. Iridectomy may be indicated in selected cases, such as patients with increased vitreous pressure, shallow anterior chambers, or the presence of voluminous air or gas in the anterior segment.

\section{REFERENCES}

1. Urrets Zavalia A Jr. Fixed, dilated pupil, iris atrophy and secondary glaucoma. Am J Ophthalmol. 1963;56:257-65.

2. Grzybowski A, Urrets-Zavalía JA, Ascaso FJ. Alberto Urrets-Zavalía Jr, MD, PhD (1920-2010). Am J Ophthalmol. 2013;155(5):957-8.

3. Davies PD, Ruben M. The paretic pupil: its incidence and aetiology after keratoplasty for keratoconus. Br J Ophthalmol. 1975;59(4):223-8.

4. Silva LRE, Gonçalves MM, Kappel GM, Gomes JAP. Iris ischemia following penetrating keratoplasty for keratoconus (Urrets-Zavalia syndrome). Cornea. 1995;14(6):618-22.

5. Jain R, Assi A, Murdoch IE. Urrets-Zavalia syndrome following trabeculectomy. Br J Ophthalmol. 2000;84:338-9.

6. Tuft SJ, Buckley RJ. Iris ischaemia following penetrating keratoplasty for keratoconus (Urrets-Zavalia syndrome). Cornea. 1995;14:618-22.

7. Espana EM, loannidis A, Tello C, et al. Urrets-Zavalia syndrome as a complication of argon laser peripheral iridoplasty. Br J Ophthalmol. 2007;91:427-9.

8. Jastaneiah S, Al-Towerki AE, Al-Assiri A. Fixed dilated pupil after penetrating keratoplasty for macular corneal dystrophy and keratoconus. Am J Ophthalmol. 2005;140: 484-9.

9. Niknam S, Rajabi MT. Fixed dilated pupil (urrets-zavalia syndrome) after deep anterior lamellar keratoplasty. Cornea. 2009;28:1187-90.

10. Uribe LE. Fixed pupil following keratoplasty evaluation of six cases. Am J Ophthalmol. 1967:63:1682-6

11. Tan AK, Humphry RC. The fixed dilated pupil after cataract surgery: is it related to intraocular use of hypromellose? Br J Ophthalmol. 1993;77:639-41.

12. Maurino $V$, Allan BD, Stevens JD, et al. Fixed dilated pupil (Urrets-Zavalia syndrome) after air/gas injection after deep lamellar keratoplasty for keratoconus. Am J Ophthalmol. $2002 \cdot 133 \cdot 266-8$
13. Minasian M, Ayliffe W. Fixed dilated pupil following deep lamellar keratoplasty (Urrets-Zavalia syndrome). Br J Ophthalmol. 2002:86:115-6.

14. Maurino V, Allan BDS, Stevens JD, Tuft SJ. Fixed dilated pupil (Urrets-Zavalia Syndrome) after air/gas injection after deep lamellar keratoplasty for keratoconus. Am J Ophthalmol. 2002:133:266-8

15. Bozkurt KT, Acar BE, Acar S. Fixed dilated pupilla as a common complication of deep anterior lamellar keratoplasty complicated with Descemet membrane perforation. Eur J Ophthalmol. 2013:23:164-70.

16. Anwar DS, Chu CY, Prasher P, et al. Features of Urrets-Zavalia syndrome after Descemet stripping automated endothelial keratoplasty. Cornea. 2012;31:1330-4.

17. Fournié $P$, Ponchel $C$, Malecaze $F$, et al. Fixed dilated pupil (Urrets-Zavalia syndrome) and anterior subcapsular cataract formation after Descemet stripping endothelial keratoplasty. Cornea. 2009;28:1184-6.

18. Russell HC, Srinivasan S. Urrets-Zavalia syndrome following Descemet's stripping endothelial keratoplasty triple procedure. Clin Experiment Ophthalmol. 2011;39:85-7.

19. Pinho SA, Cronemberg S, Calixto N. Sindrome de Urrets-Zavalia na pseudofacia. Rev Bras Oftalmol. 1994:53(4):61-5.

20. Chelnis JG, Sieminski SF, Reynolds JD. Urrets-Zavalia syndrome following goniotomy in a child. J AAPOS. 2012;16:312-3.

21. Yuzbasioglu E, Helvacioglu F, Sencan S. Fixed, dilated pupil after phakic intraocular lens implantation. J Cataract Refract Surg. 2006:32:174-6.

22. Park SH, Kim SY, Kim HI, et al. Urrets-Zavalia syndrome following iris-claw phakic intraocular lens implantation. J Refract Surg. 2008;24:959-61.

23. Pérez-Cambrodí RJ, Piñero-Llorens DP, Ruiz-Fortes JP, Blanes-Mompó FJ, Cerviño-Expósito. Fixed mydriatic pupil associated with an intraocular pressure rise as a complication of the implant of a Phakic Refractive Lens (PRL). A. Semin Ophthalmol. 2014:29(4):205-9.

24. Aralikatti AK, Tomlins PJ, Shah S. Urrets-Zavalia syndrome following intracameral C3F8 injection for acute corneal hydrops. Clin Experiment Ophthalmol. 2008;36:198-9.

25. Nizamani NB, Bhutto IA, Talpur KI. Cluster of Urrets-Zavalia syndrome: a sequel of toxic anterior segment syndrome. Br J Ophthalmol. 2013;97(8):976-9.

26. Kirkness CM, Ficker LA, Steele AD, Rice NS. The success of penetrating keratoplasty for keratoconus. Eye. 1990;4:673-88.

27. Bowden B. Keratoconus, keratoplasty and iris atrophy. Trans Ophthalmol Soc Aust. 1966;25:20-22.

28. Lagoutte F, Thienpont P, Comte P. Proposition de traitment du syndrome dUrrets-Zavalia A propos d'un cas reversible. J Fr Ophthalmol. 1983:6:291-4.

29. Gasset AR. Fixed dilated pupil following penetrating keratoplasty in keratoconus (Castroviejo syndrome). Ann Ophthalmol. 1977;9:623-8.

30. Price FW Jr. Fixed dilated pupil (Urrets-Zavalia syndrome) in corneal dystrophies. Cornea. 2005;24(3):363; author reply

31. Flament J, Schraub M, Guimaraes R, Bronner A. Urrets-Zavalia syndrome and glaucomatous cataract. Etiopathogenic and nosologic discussion. Ophthalmologica. 1984; 189(4):186-94.

32. Spierer O, Lazar M. Urrets-Zavalia syndrome (fixed and dilated pupil following penetrating keratoplasty for keratoconus) and its variants. Surv Ophthalmol. 2014;59(3): 304-10

33. Walton DS. Urrets-Zavalia syndrome following goniotomy in a child. J AAPOS. 2013 17(1):114-5.

34. Figueiredo GS, Kolli SS, Ahmad S, et al. Urrets-Zavalia syndrome following penetrating keratoplasty for keratoconus. Graefes Arch Clin Exp Ophthalmol. 2013;251:809-15.

35. Srinivasan M, Patnaik L. Fixed dilated pupil (Urrets-Zavalia syndrome) in corneal dystrophies. Cornea. 2004:23(1):81-3.

36. Spadea L, Viola M, Viola G. Regression of urrets-zavalia syndrome after deep lamellar keratoplasty for keratoconus: a case study. Open Ophthalmol J. 2008;8:130-1.

37. Mocan MC, Bozkurt B, Irkec M, et al. Urrets-Zavalia syndrome following iatrogenic pupil dilation in eyes with pigment dispersion. Can J Ophthalmol. 2009;44:216-7.

38. Bourcier T, Laplace O, Touzeau O, et al. Urrets-Zavalia syndrome. J Fr Ophtalmol. 2001 24:303-8.

39. Batista, JLA, Grisolia, ABD, Pazos HB, et al. Fixed dilated pupil (Urrets-Zavalia syndrome) after deep lamellar keratoplasty. Rev Bras Oftalmol. 2011;70(4):248-51.

40. Naumann GO. Iris ischaemia following penetrating keratoplasty for keratoconus (Urrets-Zavalia syndrome). Cornea.1997:16:120.

41. Gonzalez F, Suarez-Peñaranda JM, Diez-Feijoo E, Pazos B, Sanchez-Salorio M. Histopathological and ultrasound biomicroscopy findings in a case of irreversible mydriasis after keratoplasty in keratoconus. Acta Ophthalmol Scand. 1997:75(4):474-6.

42. Flament J, Schraub M, Guimaraes R, Bronner A. Urrets-Zavalia syndrome and glaucomatous cataract. Etiopathogenic and nosologic discussion. Ophthalmologica. 1984:189(4):186-94

43. Terry MA. The evolution of lamellar grafting techniques over twenty-five years. Cornea 2000;19(5):611-6.

44. Tzelikis PF, Santos JD, Garcez RC, Akaishi L. Deep anterior lamellar keratoplasty by big-bubble technique. Arq Bras Oftalmol. 2011:74(6):435-40.

45. Geyer O, Rothkoff L, Lazar M. Atropine in keratoplasty for keratoconus. Cornea. 1991 10:372-3.

46. Sharif KW, Casey TA. Penetrating keratoplasty for keratoconus: complications and long-term success. Br J Ophthalmol. 1991;75:142-6.

47. Terry MA, Shamie N, Chen ES, Hoar KL, Friend DJ. Endothelial keratoplasty a simplified technique to minimize graft dislocation, iatrogenic graft failure, and pupillary block. Ophthalmology. 2008;115(7):1179-86.

48. Gutman C. Atonic pupil a rare cosmetic problem in cataract patients. Euro Times. 2003; $8: 16$ 